\title{
Pallidal Deep Brain Stimulation Improves Higher Control of the Oculomotor System in Parkinson's Disease
}

\author{
Chrystalina A. Antoniades, ${ }^{1}$ Pedro Rebelo, ${ }^{2}$ Christopher Kennard, ${ }^{1}$ Tipu Z. Aziz, ${ }^{1,2}$ Alexander L. Green, ${ }^{1,2}$ \\ and James J. FitzGerald ${ }^{1,2}$ \\ ${ }^{1}$ Nuffield Department of Clinical Neurosciences and 2Nuffield Department of Surgical Sciences, University of Oxford, Oxford OX3 9DU, United Kingdom
}

The frontal cortex and basal ganglia form a set of parallel but mostly segregated circuits called cortico-basal ganglia loops. The oculomotor loop controls eye movements and can direct relatively simple movements, such as reflexive prosaccades, without external help but needs input from "higher" loops for more complex behaviors. The antisaccade task requires the dorsolateral prefrontal cortex, which is part of the prefrontal loop. Information flows from prefrontal to oculomotor circuits in the striatum, and directional errors in this task can be considered a measure of failure of prefrontal control over the oculomotor loop. The antisaccadic error rate (AER) is increased in Parkinson's disease (PD). Deep brain stimulation (DBS) of the subthalamic nucleus (STN) has no effect on the AER, but a previous case suggested that DBS of the globus pallidus interna (GPi) might. Our aim was to compare the effects of STN DBS and GPi DBS on the AER. We tested eye movements in 14 human DBS patients and 10 controls. GPi DBS substantially reduced the AER, restoring lost higher control over oculomotor function. Interloop information flow involves striatal neurons that receive cortical input and project to pallidum. They are normally silent when quiescent, but in PD they fire randomly, creating noise that may account for the degradation in interloop control. The reduced AER with GPi DBS could be explained by retrograde stimulation of striatopallidal axons with consequent activation of inhibitory collaterals and reduction in background striatal firing rates. This study may help explain aspects of PD pathophysiology and the mechanism of action of GPi DBS.

Key words: deep brain stimulation; globus pallidus interna; Parkinson's disease; saccadic eye movements; subthalamic nucleus

\section{Significance Statement}

Parkinson's disease causes symptoms including stiffness, slowness of movement, and tremor. Electrical stimulation of specific areas deep in the brain can effectively treat these symptoms, but exactly how is not fully understood. Part of the cause of such symptoms may be impairments in the way information flows from one circuit within the brain to another, as a result of overactivity of certain nerve cells. By demonstrating that stimulation of an area called the globus pallidus interna partially reverses deficits in voluntary control of eye movements, this study shows that stimulation can improve information flow between circuits, probably by calming down the overactive cells.

\section{Introduction}

The interaction between the frontal cortex and the basal ganglia in action selection has been described in terms of a set of parallel

Received June 17, 2015; revised Aug. 3, 2015; accepted Aug. 9, 2015.

Author contributions: C.A.A. and J.J.F. designed research; C.A.A., P.R., T.Z.A., A.L.G., and J.J.F. performed research; C.A.A., P.R., T.Z.A., A.L.G., and J.J.F. contributed unpublished reagents/analytic tools; C.A.A., P.R., C.K., and J.J.F. analyzed data; C.A.A., C.K., T.Z.A., A.L.G., and J.J.F. wrote the paper.

C.A.A. was supported by the National Institute of Health Research (NIHR), the Dementias and Neurodegenerative Diseases Research Network, the Oxford Biomedical Research Centre, and the Wellcome Trust. C.K. was supported by the NIHR, the Oxford Biomedical Research Centre, and the Wellcome Trust. J.J.F. was supported by the NIHR and the Oxford Biomedical Research Centre.

The authors declare no competing financial interests.

Correspondence should be addressed to either of the following: Dr. Chrystalina A. Antoniades, Nuffield Department of Clinical Neurosciences, Level 6, West Wing, John Radcliffe Hospital, University of Oxford OX3 9DU, UK, E-mail: chrystalina.antoniades@ndcn.ox.ac.uk; or Dr. James J. FitzGerald, Nuffield Department of Surgical Sciences, University of 0xford, Oxford 0X3 9DU, UK, E-mail: james.fitzgerald@nds.ox.ac.uk. but mostly segregated cortico-basal ganglia (CBG) loops (Alexander et al., 1986). Each involves certain regions of the frontal cortex and corresponding parts of the nuclei of the basal ganglia. Motor, oculomotor, prefrontal, and limbic loops have been defined. The motor and oculomotor loops control body and eye movements. Prefrontal and limbic loops subserve more complex aspects of action selection such as response inhibition and reward processing. In order for such higher functions to influence action selection, information from these loops must feed into the motor and oculomotor loops. The striatum seems to be a key structure in this process, containing areas particular to each loop but also extensive regions of overlap (Draganski et al., 2008; Averbeck et al., 2014). Electrophysiological evidence for interloop transfer of 
Prosaccadic paradigm

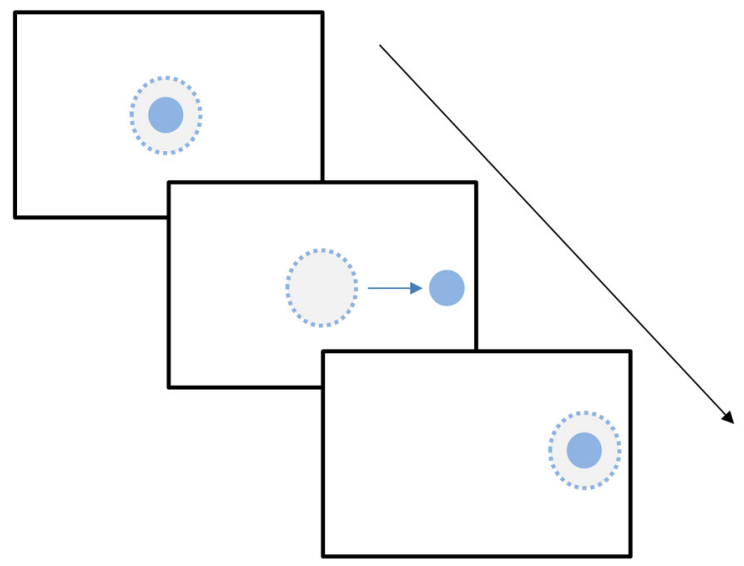

Antisaccadic paradigm

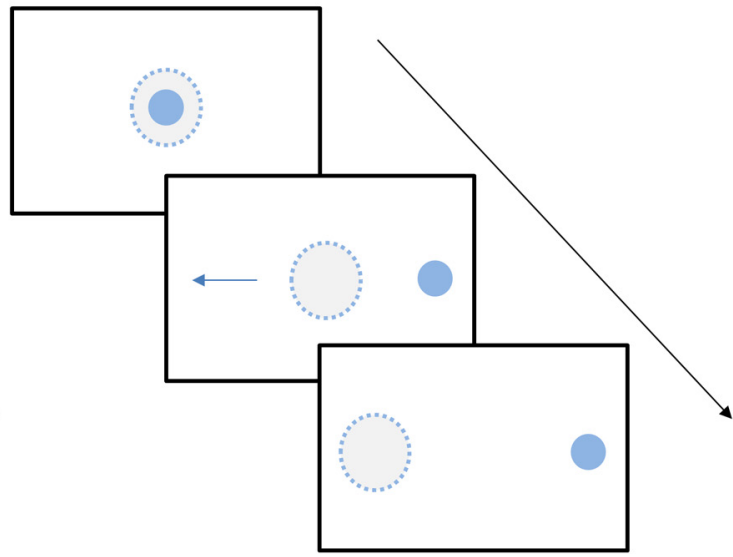

Figure 1. Oculomotor task. The filled circle represents the stimulus, and the dashed circle represents gaze location. Left, Prosaccadic paradigm. Participants were instructed to move their eyes to the new target position that was randomly either to the left or to the right. Right, Antisaccadic paradigm. Participants were instructed to move their eyes in the opposite direction to the movement of the stimulus.

information in the striatum from limbic to motor circuits has been found in monkeys (Pasquereau et al., 2007).

Saccadic tasks are objectively quantifiable and are a sensitive way of evaluating aspects of the function of CBG circuits. Performance in simple "reflexive" prosaccades (looking toward a visual stimulus) may represent function purely within the oculomotor loop. The more complex antisaccade task (looking away from a visual stimulus; Hallett, 1978) requires inhibition of the normal reflexive response, which is known to require the dorsolateral prefrontal cortex, part of the prefrontal loop (DeSouza et al., 2003; Munoz and Everling, 2004; Pierrot-Deseilligny et al., 2004). The antisaccadic error rate (AER) quantifies how often a subject erroneously makes prosaccades rather than antisaccades during an antisaccade task and is thus a measure of failure of response inhibition. An elevated AER may, therefore, reflect impairment of information transfer from the prefrontal to the oculomotor loop.

In Parkinson's disease (PD), the latency for prosaccades is prolonged, particularly in more advanced disease (Chan et al., 2005; Amador et al., 2006; Antoniades et al., 2013b). Importantly, the AER is also significantly increased (Rivaud-Péchoux et al., 2007; Terao et al., 2013), even in some newly diagnosed cases (Kitagawa et al., 1994; Antoniades et al., 2015), suggesting that defects in interloop information transfer are present from an early stage.

Deep brain stimulation (DBS) relieves the motor symptoms of $\mathrm{PD}$, including rigidity, bradykinesia, and tremor (Krack et al., 2003). The most common DBS targets for PD are the globus pallidus pars interna (GPi) and subthalamic nucleus (STN) (Rodriguez-Oroz et al., 2005), but the mechanism by which DBS at these sites exerts its therapeutic effects is uncertain (Montgomery and Gale, 2008). Simple explanations based on analogies with lesional surgery are now regarded as inaccurate. Whether the actual target of stimulation is cell bodies within the nucleus where the active electrode is sited, axons afferent to it, axons efferent from it, or a combination of these, is not entirely clear.

STN DBS can reduce prosaccadic latency (PSL; Temel et al., 2008, 2009; Antoniades et al., 2012), suggesting an amelioration of dysfunction within the oculomotor loop, but has had no effect on the AER in previous studies (Fawcett et al., 2010; Yugeta et al., 2010), which suggests that the dysfunction in the input to the oculomotor loop from higher circuits is unaffected. Saccades in GPi DBS have been studied far less extensively, but, very interestingly, a report of a single case in 1998 suggested that the AER might be improved by stimulation (Straube et al., 1998). This was not replicated in a GPi DBS patient with Huntington's disease (Fawcett et al., 2005), but the number of trials was small and the pathology very different. To investigate this, we measured saccadic parameters in three groups: PD patients with GPi DBS, PD patients with STN DBS, and healthy controls. Measurements were made with DBS systems on and off. We demonstrate here that GPi DBS, but not STN DBS, partially reverses the deleterious impact of PD on the AER, and we suggest a possible mechanism for this.

\section{Materials and Methods}

Subjects. This study was conducted in the John Radcliffe Hospital (Oxford, United Kingdom) and was approved by the ethics committee (REC reference 04/Q0406/60). Written informed consent was obtained from all participants after the procedures were explained to them.

Fourteen PD patients and 10 age-matched healthy controls participated in the study. Eight patients had undergone bilateral GPi DBS [seven males; mean age, 64 years old (range, 54-77)], and six patients underwent bilateral STN DBS [all males; mean age, 61 years old (range, 47-73)]. All patients had Medtronic DBS electrodes: type 3389 in STN DBS patients and type 3387 in GPi DBS patients.

To exclude medication effects as far as possible, all testing was done in the ON medication state 60-90 min after dose.

The healthy controls had no history of neurological disorders and were not taking any medication at the time of the examination.

Oculomotor tasks. Visually guided horizontal saccadic eye movements were recorded using an infrared head-mounted oculometer, with three built-in lasers projecting red spots in a horizontal line in the midline and at $\pm 10^{\circ}$ (Antoniades et al., 2012). We used a previously described antisaccadic protocol (Antoniades et al., 2013a; see Fig. 1 for an illustration of the task). After an initial calibration set consisting of 12 prosaccades ( 6 to the right and 6 to the left), this protocol consisted of five blocks as follows: a block of 60 prosaccades, three blocks of 40 antisaccades, and a final block of 60 prosaccades, with a break of 1 min between blocks. For both prosaccades and antisaccades, a central fixation target was displayed for a random foreperiod of 1.0-2.0 s. Then one of the peripheral targets chosen randomly either to the left or right was presented, and the central stimulus was simultaneously removed. The peripheral target remained illuminated until $200 \mathrm{~ms}$ after the end of the ensuing saccade. For pro- 
Table 1. Details of PD patients

\begin{tabular}{|c|c|c|c|c|c|c|}
\hline$\overline{\text { ID }}$ & Age & Sex & Year of diagnosis & Medications & UPDRS III DBS OFF & UPDRS III DBS ON \\
\hline STN1 & 58 & M & 2004 & Sinemet, amantadine & 64 & 36 \\
\hline STN2 & 73 & M & 2001 & Madopar, rotigotine, entacapone, rasagiline & 26 & 10 \\
\hline STN3 & 63 & M & 1994 & Ropinirole, amitriptyline & 55 & 37 \\
\hline STN5 & 59 & M & 1996 & Madopar, Stalevo & 39 & 27 \\
\hline STN6 & 47 & M & 2009 & Madopar, rotigotine, rasagiline & 45 & 27 \\
\hline GPi1 & 58 & M & 2003 & Sinemet, pramipexole & 41 & 33 \\
\hline GPi4 & 64 & M & 2003 & Madopar & 31 & 22 \\
\hline GPi5 & 58 & M & 1998 & Sinemet, Stalevo, rotigotine, amantadine & 19 & 11 \\
\hline GPi6 & 67 & M & 2006 & Sinemet, Stalevo & 35 & 19 \\
\hline GPi7 & 62 & M & 2007 & Sinemet & 40 & 21 \\
\hline GPi8 & 54 & M & 2005 & Madopar, amantadine, entacapone, rasagiline & 30 & 25 \\
\hline
\end{tabular}

Unified Parkinson's Disease Rating Scale (UPDRS) part III scores are with DBS on and off (patients were on their medication in both cases). Sinemet contains levodopa and carbidopa; Stalevo contains levodopa, carbidopa, and entacapone; and Madopar contains levodopa and benserazide. M, Male; F, female.

saccades, subjects were instructed to make a saccade quickly to the new target position. For the antisaccades, subjects were instructed to make a saccade in the opposite direction.

Data and statistical analysis. For each subject, saccadic data were analyzed using LatencyMeter (version 4.14; Ober Consulting). This software determines the saccadic latency using a saccade-detection algorithm based on velocity and acceleration. For each participant, we calculated mean prosaccadic and antisaccadic latencies and error rates for antisaccades. The AER was defined as the percentage of directional errors, i.e., saccades triggered toward the lateral target. Saccades with latencies $<80$ $\mathrm{ms}$ or over $1000 \mathrm{~ms}$ were excluded from the analysis (this represented $<1 \%$ of all saccades).

Stimulation-induced changes in latency and AER were not expected to be normally distributed; therefore, nonparametric statistics were used. To compare paired data (e.g., the value of a certain saccadic parameter with stimulation OFF and ON), the Wilcoxon signed rank test (WSRT) was used. To compare unpaired data (e.g., the difference between the effects of STN and GPi stimulation on a particular saccadic parameter), the Mann-Whitney $U$ test was used.

\section{Results}

The demographic details and Unified Parkinson's Disease Rating Scale (UPDRS) part III scores of the STN DBS and GPi DBS patients are shown in Table 1, and the details of their stimulation, including lead tip coordinates, contacts used, and stimulator settings, are shown in Table 2.

\section{Prosaccades and antisaccades in healthy control participants} Figure 2, $A$ and $B$, shows tracings of the prosaccades and antisaccades, respectively, of a healthy control participant. Each curve represents the trajectory of a single saccade. Both leftward and rightward saccades are shown as upward-going traces. In the antisaccade plot, correctly executed antisaccades are shown as upward-going traces, whereas erroneous prosaccades are downward-going. The mean PSL was $186 \mathrm{~ms}$ in the control group. The mean antisaccadic latency (ASL) was $328 \mathrm{~ms}$, and the mean AER was 19\%.

\section{Effects of STN and GPi DBS on prosaccades}

Figure 2, $C$ and $E$, shows the prosaccades of an STN DBS patient with DBS OFF (Fig. 2C) and ON (Fig. 2E). In line with previous published studies, STN DBS reduced mean prosaccadic latency. This can be seen as a left shift of the distribution of prosaccades in Fig. 2E compared with Fig. 2C. Figure 2, G and $I$, shows the same thing for a GPi patient, i.e., a left shift of the distribution in Fig. $2 I$ (DBS ON) compared with Fig. $2 G$ (DBS OFF).
Table 2. Electrode locations and stimulation parameters

\begin{tabular}{|c|c|c|c|c|c|c|c|c|}
\hline \multirow[b]{2}{*}{ ID } & \multirow[b]{2}{*}{ Side } & \multicolumn{3}{|c|}{$\begin{array}{l}\text { Lead tip coordinates } \\
\text { (mm with respect } \\
\text { to mid AC-PC line) }\end{array}$} & \multirow[b]{2}{*}{$\begin{array}{l}\text { Contacts } \\
\text { used }\end{array}$} & \multirow[b]{2}{*}{$\begin{array}{l}\text { Amplitude } \\
\text { (V) }\end{array}$} & \multirow{2}{*}{$\begin{array}{l}\text { Pulse } \\
\text { width } \\
(\mu s)\end{array}$} & \multirow[b]{2}{*}{$\begin{array}{l}\text { Frequency } \\
(\mathrm{Hz})\end{array}$} \\
\hline & & $\begin{array}{l}\text { AP } \\
(y)\end{array}$ & $\begin{array}{l}\text { Lateral } \\
(x)\end{array}$ & $\begin{array}{l}\text { Vertical } \\
\text { (z) }\end{array}$ & & & & \\
\hline \multirow[t]{2}{*}{ STN1 } & L & -4.6 & -11.2 & -6.2 & $C+, 3-$ & 3.8 & 110 & 130 \\
\hline & $\mathrm{R}$ & -4.9 & 11.2 & -7.0 & $9-, 11+$ & 3.4 & 120 & 130 \\
\hline \multirow[t]{2}{*}{ STN2 } & $\mathrm{L}$ & -3.2 & -12.8 & -5.5 & $C+, 2-$ & 3.2 & 60 & 120 \\
\hline & $\mathrm{R}$ & -1.8 & 13.8 & -6.3 & $9+, 10-$ & 2.0 & 60 & 120 \\
\hline \multirow[t]{2}{*}{ STN3 } & $\mathrm{L}$ & -2.9 & -10.5 & -8.5 & $C+, 3-$ & 3.0 & 60 & 180 \\
\hline & $\mathrm{R}$ & -3.8 & 10.5 & -6.5 & $C+, 8-$ & 4.0 & 120 & 180 \\
\hline \multirow[t]{2}{*}{ STN4 } & $\mathrm{L}$ & -3.7 & -11.8 & -9.4 & $1+, 2+, 3-$ & 3.0 & 110 & 180 \\
\hline & $\mathrm{R}$ & -4.9 & 12.4 & -5.4 & $8-, 9-, 10+$ & 3.6 & 110 & 180 \\
\hline \multirow[t]{2}{*}{ STN5 } & $\mathrm{L}$ & -3.6 & -11.8 & -4.6 & $C+, 0-$ & 3.7 & 90 & 130 \\
\hline & $\mathrm{R}$ & -2.0 & 12.7 & -6.4 & $C+, 9-$ & 3.6 & 60 & 130 \\
\hline \multirow[t]{2}{*}{ STN6 } & $\mathrm{L}$ & -2.7 & -12.0 & -8.9 & $1+, 2-$ & 2.8 & 60 & 160 \\
\hline & $\mathrm{R}$ & -3.1 & 11.2 & -7.8 & $8-, 9-, 10+$ & 3.2 & 70 & 160 \\
\hline \multirow[t]{2}{*}{ GPi1 } & $\mathrm{L}$ & 3.6 & -19.6 & -4.7 & $1-, 2+$ & 3.0 & 90 & 130 \\
\hline & $\mathrm{R}$ & 2.0 & 19.2 & -3.0 & $9+, 10-$ & 1.8 & 80 & 130 \\
\hline \multirow[t]{2}{*}{ GPi2 } & $\mathrm{L}$ & 2.2 & -19.8 & -7.1 & $2-, 3+$ & 3.7 & 170 & 130 \\
\hline & $\mathrm{R}$ & 2.4 & 20.8 & -6.9 & $10-, 11+$ & 3.7 & 150 & 130 \\
\hline \multirow[t]{2}{*}{ GPi3 } & $\mathrm{L}$ & 1.5 & -22.0 & -2.4 & $0-, 2+$ & 4.0 & 150 & 130 \\
\hline & $\mathrm{R}$ & 2.1 & 19.3 & -2.3 & $8-, 10+$ & 4.1 & 210 & 130 \\
\hline \multirow[t]{2}{*}{ GPi4 } & $\mathrm{L}$ & 2.9 & -19.8 & -3.0 & $C+, 1-$ & 3.3 & 170 & 130 \\
\hline & $\mathrm{R}$ & 3.4 & 21.1 & -3.0 & $C+, 8-$ & 3.8 & 200 & 130 \\
\hline \multirow[t]{2}{*}{ GPi5 } & $\mathrm{L}$ & 3.7 & -19.0 & -4.4 & $1-, 2+$ & 3.8 & 110 & 130 \\
\hline & $\mathrm{R}$ & 5.7 & 21.3 & -3.7 & $9-, 10+$ & 3.6 & 110 & 130 \\
\hline \multirow[t]{2}{*}{ GPi6 } & $L$ & 2.1 & -19.8 & -4.9 & $C+, 3-$ & 2.5 & 140 & 130 \\
\hline & $\mathrm{R}$ & 3.4 & 19.3 & -3.0 & $8-, 9+$ & 3.3 & 120 & 130 \\
\hline \multirow[t]{2}{*}{ GPi7 } & $\mathrm{L}$ & 4.6 & -19.0 & -3.9 & $1-, 2+$ & 3.5 & 140 & 130 \\
\hline & $\mathrm{R}$ & 4.9 & 19.4 & -6.2 & $9-, 10+$ & 3.5 & 150 & 130 \\
\hline \multirow[t]{2}{*}{ GPi8 } & $\mathrm{L}$ & 2.1 & -21.1 & -3.1 & $1-, 2+$ & 2.5 & 90 & 130 \\
\hline & $\mathrm{R}$ & 2.2 & 19.6 & -4.3 & $8+, 9-, 10+$ & 1.8 & 90 & 130 \\
\hline
\end{tabular}

$\mathrm{AC}$, Anterior commissure; $P C$, posterior commissure; L, left; R, right. For contact numbering, left lead contacts are $0-3$ ( 0 being nearest the tip), and right lead contacts are $8-11$ ( 8 being nearest the tip); ( is casing of the implanted pulse generator, used as the anode in monopolar stimulation configurations.

Prosaccadic data are summarized in the top row of Figure 3. In the six STN DBS patients, the overall mean PSL for the group was $245 \mathrm{~ms}$ with the stimulator system off, and this was reduced to $203 \mathrm{~ms}$ with stimulation, a mean reduction of $41.4 \mathrm{~ms}(16 \%)$ $(p=0.031$, WSRT). Likewise, in the eight GPi DBS patients, stimulation reduced the overall mean PSL from 230 to $206 \mathrm{~ms}$, a mean reduction of $23.9 \mathrm{~ms}(11 \% ; p=0.0078$, WSRT $)$. The difference in the effects of STN DBS and GPi DBS on PSL was not statistically significant ( $p=0.11$, Mann-Whitney $U$ test). 
PROSACCADES
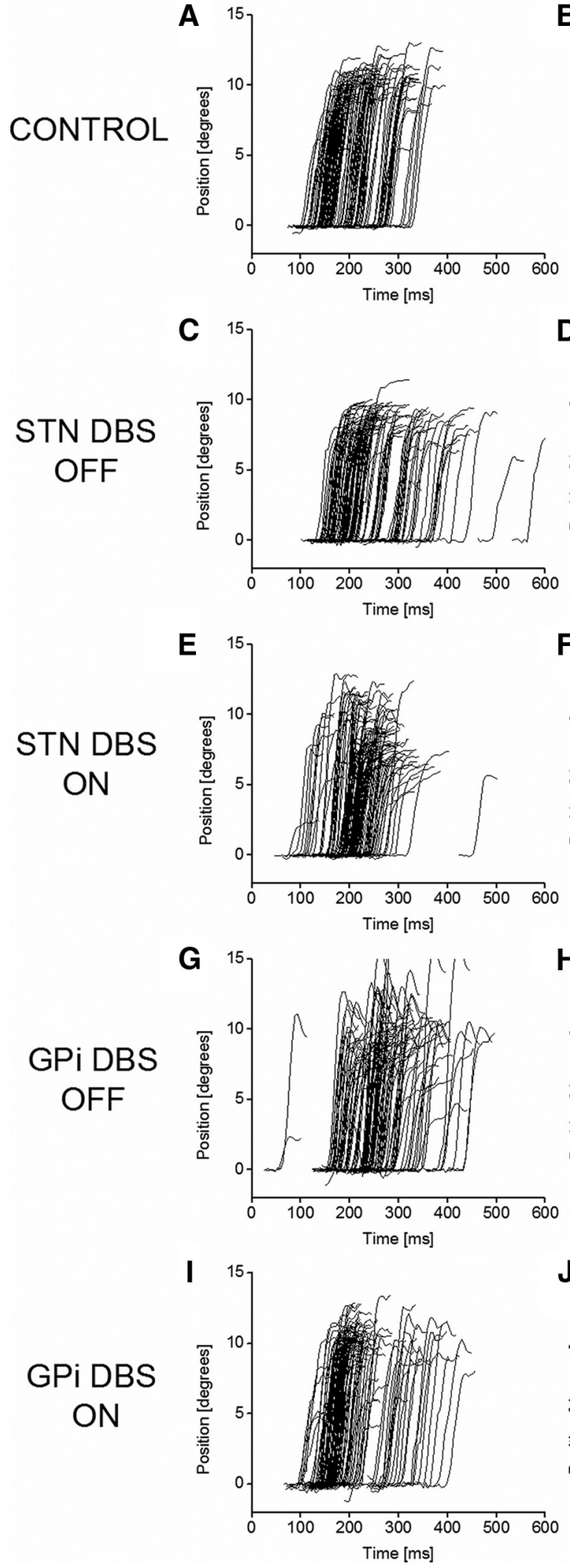

ANTISACCADES
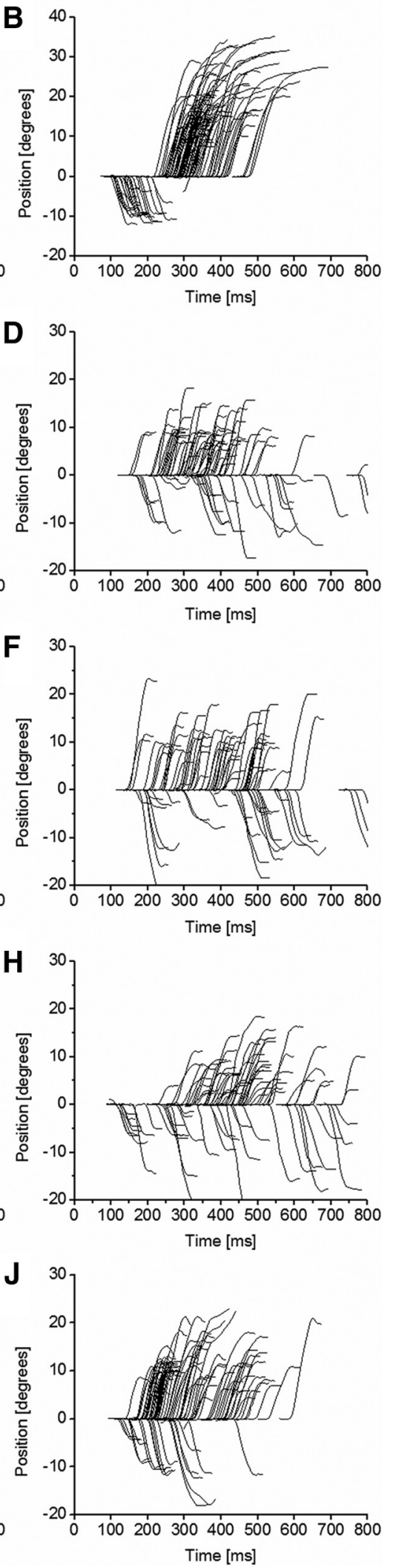

Figure 2. Saccade trajectories in example controls and patients having DBS of STN and GPi. The left column shows prosaccades, and the right column shows antisaccades. Both leftward and rightward saccades are shown. For antisaccades, erroneous prosaccades are shown as downward deflections to negative amplitude values. $\boldsymbol{A}, \boldsymbol{B}$, Healthy control; $\boldsymbol{C}, \boldsymbol{D}$, STN DBS patient with system OFF; $\boldsymbol{E}, \boldsymbol{F}$, STN DBS patient with system ON; $\boldsymbol{G}, \boldsymbol{H}, \mathrm{GPi}$ DBS patient with system OFF; I, J, GPi DBS patient with system ON. Comparison of $\boldsymbol{E}$ with $\boldsymbol{C}$ and $\boldsymbol{I}$ with $\boldsymbol{G}$ shows that stimulation of either target left-shifts the distribution of latencies for prosaccades toward more normal values $(\boldsymbol{A})$. Comparison of $\boldsymbol{J}$ with $\boldsymbol{H}$ shows that stimulation of $\mathrm{GPi}$ reduces the antisaccadic error rate, whereas comparison of $\boldsymbol{F}$ with $\boldsymbol{D}$ shows that stimulation of STN does not. 

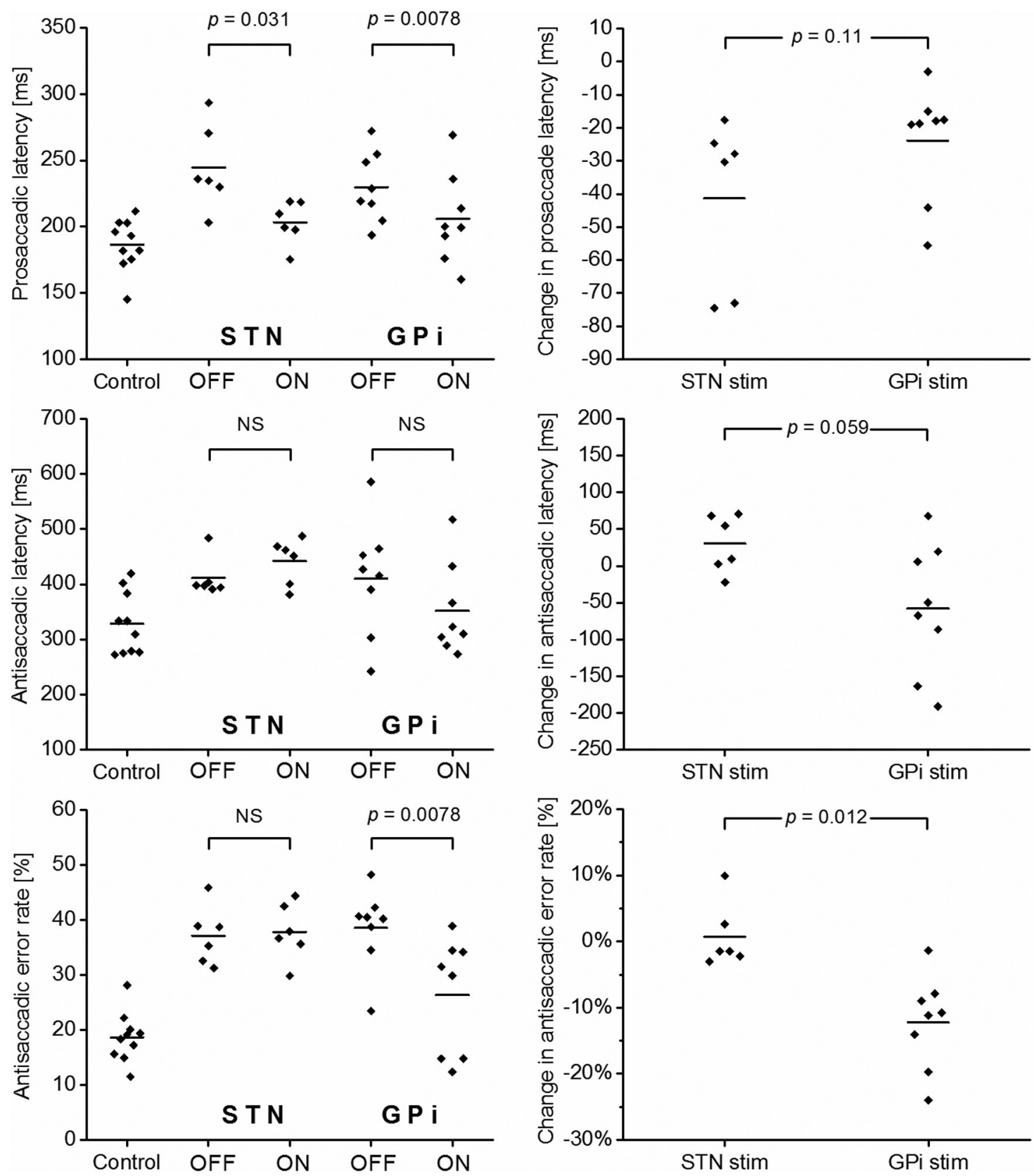

Figure 3. Saccadic latencies and error rates for all 24 study participants. Top row, Prosaccadic latencies; middle row, antisaccadic latencies; bottom row, antisaccadic error rates. In each row, the left graph shows data for controls, STN DBS patients with stimulation OFF, STN patients with stimulation ON, GPi patients with stimulation OFF, and GPi patients with stimulation ON. OFF versus ON comparisons use the Wilcoxon signed rank test. In each row, the right graph shows the change in the relevant saccadic parameter affected by STN stimulation (stim) and GPi stimulation. GPi versus STN comparisons use the Mann-Whitney $U$ test. The horizontal bars represent the mean for each group of data points.

Effects of STN and GPi DBS on antisaccades

Antisaccadic latency was affected differently by STN DBS and GPi DBS. Data are shown in Figure 3 (middle row). STN DBS tended to lengthen the ASL, whereas GPi DBS tended to shorten it. However, neither of these effects was statistically significant. For STN DBS patients, the overall mean ASL was 411 ms with DBS OFF and $442 \mathrm{~ms}$ with DBS ON, a mean increase of $30.5 \mathrm{~ms}$ ( $8 \%$, not significant). For GPi DBS patients, the overall mean ASL was 408 $\mathrm{ms}$ with DBS OFF and $340 \mathrm{~ms}$ with DBS ON, a mean reduction of $67.3 \mathrm{~ms}$ (16\%, not significant).

Data on the antisaccadic error rate are shown in Figure 3 (bottom row). In patients with STN DBS, the AER was unchanged by stimulation (37\% with DBS OFF and 38\% with DBS
ON, not significant). In contrast, in patients with GPi DBS, stimulation produced a clear reduction in the AER from 39\% to $26 \%$ $(p=0.0078$, WSRT). Superficially, this appears to be a reduction in the AER of one-third. However, this understates the case because the healthy control patients had a mean AER of $19 \%$. A more appropriate measure of the deleterious effects of PD is probably the "excess" in the AER in patients compared with controls. In GPi DBS patients with stimulation OFF (AER, 39\%), this excess is $20 \%$. With the stimulator ON (AER, 26\%), the excess is $7 \%$. Thus, the excess in the AER compared with healthy controls is reduced by two-thirds with GPi DBS.

Figure 2, $H$ and $J$, shows an example of the antisaccades of a GPi DBS patient with stimulation OFF (Fig. $2 H$ ) and ON (Fig. 


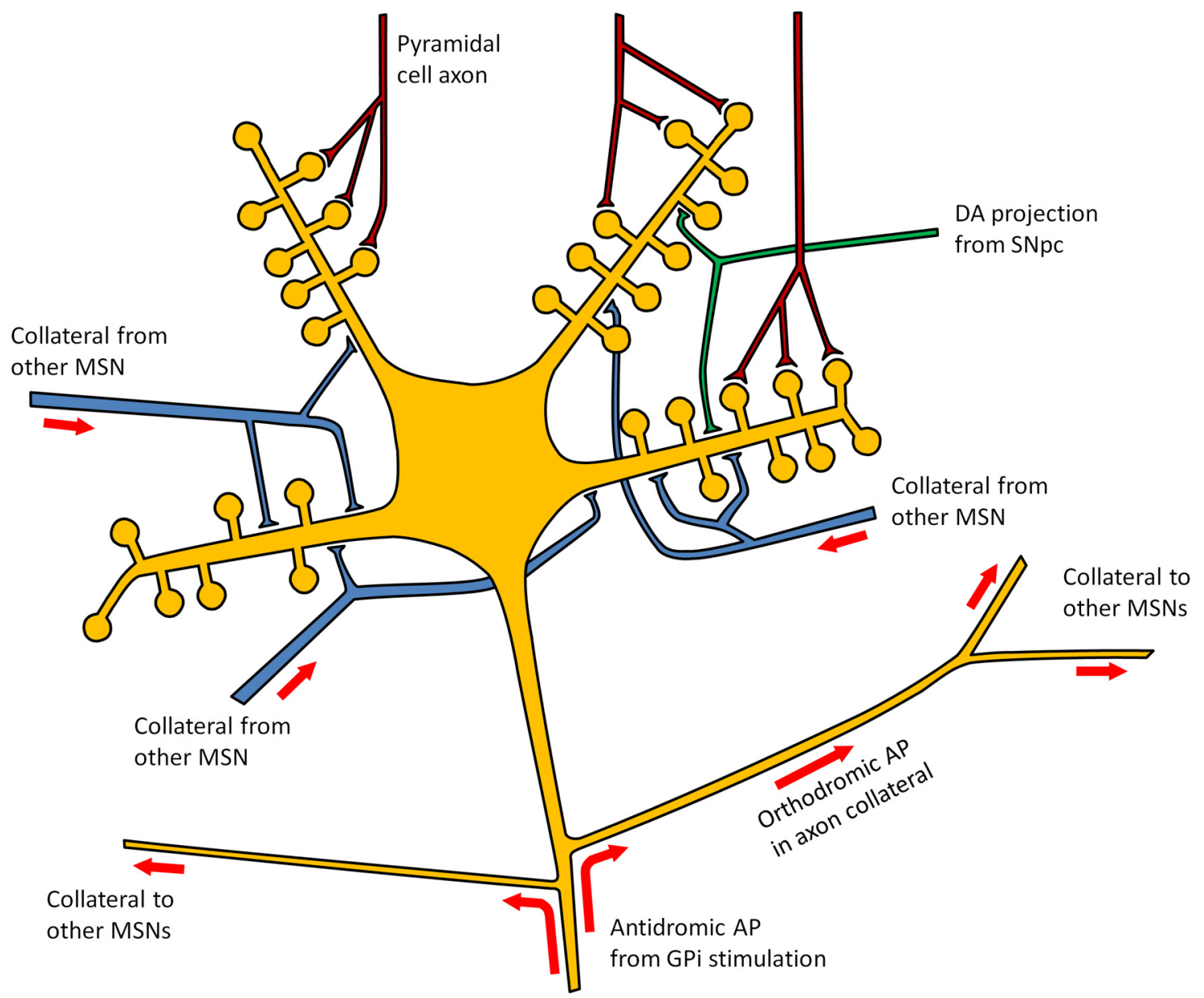

Figure 4. Schematic illustration of "striatal damping" by antidromic activation of striatopallidal axons. DA, dopaminergic; SNpc, substantia nigra pars compacta.

$2 J$ ). The number of erroneous prosaccades (shown as downward-going deflections to negative degree values) is clearly lower in Figure 2J. A similar example for an STN DBS patient is shown in Figure 2, $D$ (stimulation OFF) and $F$ (stimulation $\mathrm{ON}$ ). In this case, there is no reduction in the proportion of prosaccades.

\section{Discussion}

We have demonstrated a qualitative difference in the oculomotor effects of DBS of the GPi and the STN. As in previous studies (Rivaud-Péchoux et al., 2000; Fawcett et al., 2010; Yugeta et al., 2010), STN DBS reduced prosaccadic latencies but left antisaccadic error rates unaffected. In contrast, GPi DBS produced a consistent and statistically significant reduction in antisaccadic error rate.

Correctly executing an antisaccade requires inhibition of the normal reflexive prosaccade response and generation of a volitional response in the opposite direction. Inhibition is never perfect, and the healthy controls here had a mean AER of 19\%. In the GPi DBS patients, the AER averaged 38\% with stimulation off. The reduction to a mean of $28 \%$ with GPi stimulation could, in theory, be brought about in two ways: by improving the ability of prefrontal circuits to control the oculomotor generator or by inhibiting the competing prosaccade response. However, rather than inhibiting prosaccades, GPi DBS consistently reduced prosaccadic latency, similarly to STN DBS. This strongly suggests that the decrease in AER with GPi DBS is attributable to a strengthening of prefrontal CBG loop influence over the oculomotor loop. There was a trend with GPi DBS to lower antisaccadic latencies, although this did not reach statistical significance. Like prosaccade inhibition, the initiation of a volitional saccade depends on prefrontal input to the oculomotor loop, and a reduction in ASL would fit well with the observed reduction in AER.

Interloop information transfer probably occurs in the striatum (Haber et al., 2006; Draganski et al., 2008; Averbeck et al., 2014). Striatal medium spiny neurons (MSNs) receive cortical glutamatergic input and send GABAergic projections to the pallidum and substantia nigra. MSNs in normal brains fire at very low rates: in monkeys, firing is at $0.5-2 \mathrm{~Hz}$ and is in the form of task-related activity separated by near silence (Kimura, 1986, 1992; Aosaki et al., 1994). Recent computational work (Guthrie et al., 2013) suggests that this intrinsically low firing rate is a key requirement for faithful interloop information transfer. In $\mathrm{PD}$, MSN firing rates are far higher than normal. MSNs in parkinsonian monkeys fire spontaneously at mean rates of around 23-30 Hz (Liang et al., 2008; Singh et al., 2015). Abnormally high MSN firing rates in PD could, therefore, account for degradation of interloop information transfer and the consequent elevated AER.

MSN axons send an extensive arborization of recurrent collaterals to form inhibitory GABAergic synapses on large numbers of other MSNs (Wilson and Groves, 1980; Bolam et al., 1983; 

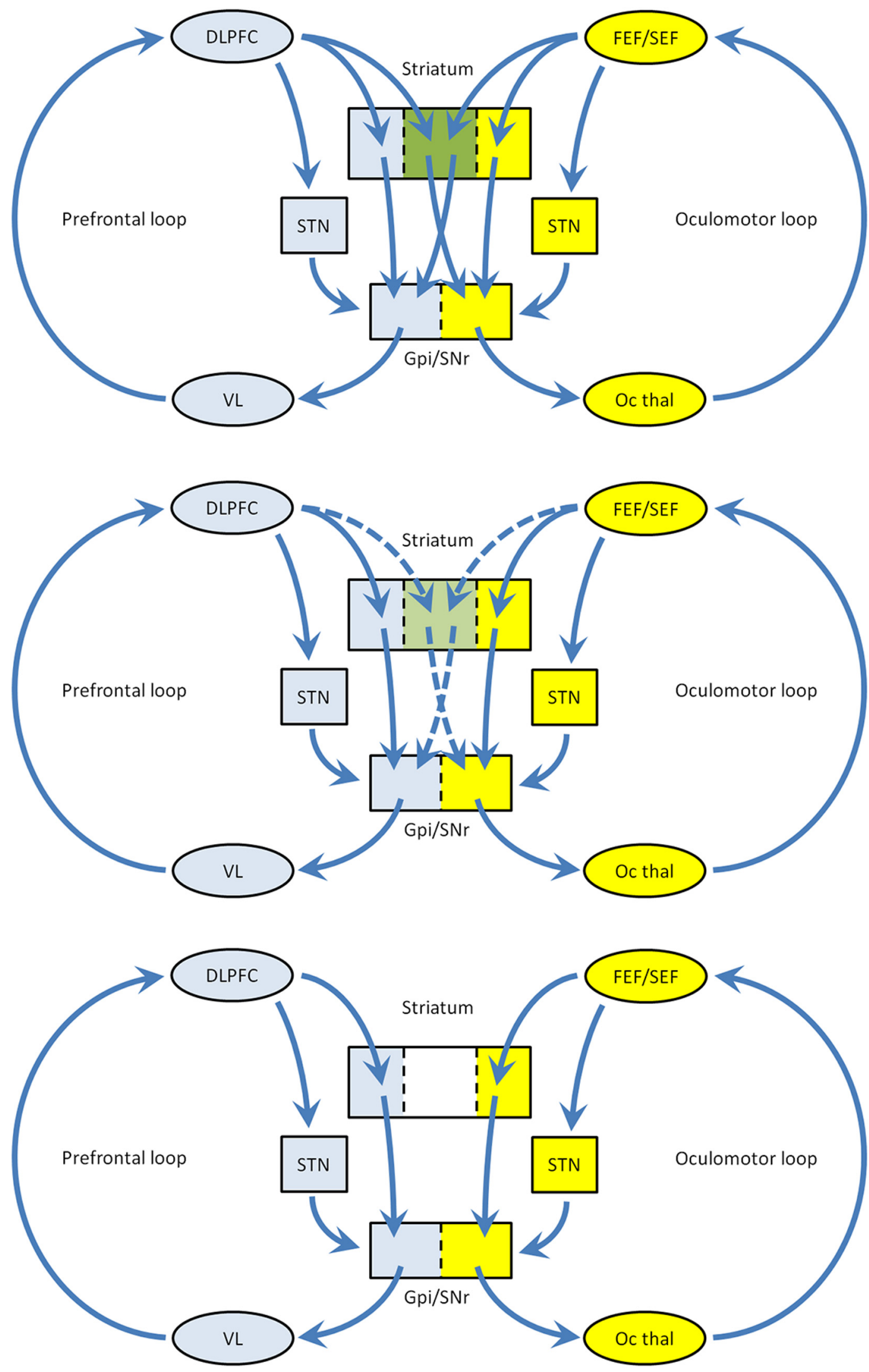

Figure 5. Simplified model of impairment of information flow between the prefrontal and oculomotor loops. Top, In the normal situation, there is mixing in the associative areas of striatum (green) permitting the prefrontal loop to influence the oculomotor loop. Middle, Parkinsonian on state: degraded interloop transfer through medium spiny neuron overactivity. Bottom, Parkinsonian off state: extreme abnormality of MSN activity results in complete failure of interloop information transfer, leaving the two loops isolated. DLPFC, Dorsolateral prefrontal cortex; VL, ventrolateral thalamus; FEF, frontal eye field; SEF, supplementary eye field; $\mathrm{SNr}$, substantia nigra pars reticulata; 0 c thal, oculomotor thalamus. 
Kawaguchi et al., 1990). The exact function of this collateral network in healthy brains remains uncertain. However, animal models suggest that in $\mathrm{PD}$, there is dramatic downregulation of recurrent collateral spiny-spiny inhibitory connections (Taverna et al., 2008). This generalized reduction in inhibition may be a factor in the elevation of MSN firing rates.

One mechanism by which DBS might work is stimulation of axons afferent to the nucleus where the electrode is sited (Montgomery and Gale, 2008). This will send antidromic action potentials (APs) to the upstream nucleus. Pallidal stimulation in animals can evoke antidromic APs in MSN axons. On reaching the collateral branch point, they propagate orthodromically into collaterals (Fig. 4), causing GABA release at spiny-spiny synapses (Guzman et al., 2003; López-Huerta et al., 2013). Although such synapses may not individually be strong, MSNs may each receive over 1300 collateral connections (Guzman et al., 2003). We hypothesize that the generation of antidromic APs in many MSN axons by GPi stimulation activates very large numbers of spinyspiny synapses, causing widespread MSN inhibition, bringing down spontaneous MSN firing rates and thereby improving interloop information transfer.

This hypothesis is supported by the fact that other DBS or lesional procedures for PD have no influence on the AER. As discussed above, STN DBS does not affect the AER. Pallidotomy is now rarely performed, and so we could not include it in this study for direct comparison; however, data from a group of 31 patients, whose saccades were measured using similar equipment to that used here, showed no change in the AER after pallidotomy (Blekher et al., 2000). Neither of these other treatments could directly modulate MSN activity. Levodopa, which acts on the MSN directly, does improve the AER (Hood et al., 2007) and also decreases the error rate in a memory-guided saccade (MGS) task (Vermersch et al., 1994), which also requires prefrontal input to the oculomotor circuit. Thus, transfer of information from prefrontal to oculomotor circuits is improved by treatments that act directly on the MSN but not by those that do not. Interestingly, a large STN DBS study that showed no effect on the AER did show a reduction of another type of erroneous saccade, namely saccades to cue in the MGS task (Yugeta et al., 2010). This apparent paradox may perhaps be explained by the fact that in the MGS task, unlike the antisaccade task, the fixation target is still present when the erroneous saccade occurs. PD impairs fixation (Pinnock et al., 2010), and STN DBS appears to improve it (Wark et al., 2008). Thus, the reduction in saccades to cue may reflect an improvement in fixation rather than in prefrontal inhibitory input.

The dampening effect of stimulation-induced GABA release has a time course that is in remarkable harmony with the interpulse period at standard clinical DBS frequencies. In nonhuman primates, STN DBS reduced firing rates of STN neurons (Meissner et al., 2005), and this was attributed to stimulation of axons afferent to the STN with consequent GABA release. Neurons were silenced for $2.9 \mathrm{~ms}$ after a stimulus pulse, after which firing rates increased again in sigmoidal fashion, reaching the prestimulus baseline at $7 \mathrm{~ms}$. The interpulse interval at the most commonly used frequency clinically $(130 \mathrm{~Hz})$ is $7.7 \mathrm{~ms}$; thus, firing of the neurons receiving the GABA inhibition was reduced for almost this entire period.

Alternative mechanisms for the improvement in the AER must, of course, be considered. First, the GPi receives projections from the STN that might be activated antidromically just like the MSN axons. However, given that direct neuromodulation of the
STN does not affect the AER in either direction, it seems unlikely that indirectly modulating it by retrograde stimulation would do so. Second, pallidal neurons activated by DBS might modulate MSN behavior via pallidostriatal projections (Staines et al., 1981). However, these neurons would be damaged by pallidotomy, and therefore one might expect pallidotomy to affect the AER, yet it does not. Third, GPi stimulation might inhibit the thalamus, reducing drive to cortex and thereby reducing glutamatergic stimulation of MSNs, which might also lower their activity. Three things argue against this. First, GPi activity is increased by STN stimulation (Hashimoto et al., 2003), so if the reduction in the AER was mediated this way, it is again curious that STN stimulation does not have any effect. Second, if increased drive to the thalamus reduced the AER, one might expect reduced drive to the thalamus to do the opposite, yet pallidotomy has no effect. Third, the pathological increase in the firing rate of MSNs in PD is not activity dependent but rather spontaneous (Singh et al., 2015). Reducing cortical glutamatergic stimulation to the MSNs would not, therefore, stop their pathological firing.

Pallidal neurons have been found in monkeys whose activity is modulated in relation to saccades (Yoshida and Tanaka, 2009). Strikingly, activity is modulated much more in relation to antisaccades than prosaccades, and there appear to be neurons concerned with prosaccade inhibition and others concerned with volitional saccade generation (Yoshida and Tanaka, 2015). DBS is unlikely to be affecting such cells directly in the human because most are in the external segment of the pallidum rather than the internal segment and because experimental disruption of their function worsened rather than improved antisaccadic performance. It seems more likely that GPi DBS acts to improve the quality of the input these cells receive from the striatum, enabling them to function more effectively.

Patients with minimal motor problems can have significantly impaired antisaccades (Antoniades et al., 2015), suggesting that interloop signals in the striatum are weaker than within-loop signals (Guthrie et al., 2013) and are, therefore, more sensitive to striatal noise. The parkinsonian off state may reflect striatal noise that is bad enough to completely disrupt interloop signals. MSNs in primates with chronic PD are observed to fire in an abnormal bursting pattern when in the parkinsonian off state (Singh et al., 2015). Levodopa suppresses the bursting, and this coincides with transition to the on state, although firing rates remain higher than in normal animals. Figure 5 illustrates three possible striatal states according to this model, ranging from no noise (normal brain) through moderate levels of noise (parkinsonian on state) to high levels of noise (parkinsonian off state).

This study may help shed light on both the nature of parkinsonian pathophysiology and the mechanism of action of GPi DBS used to treat it. The improvement in information transfer between higher circuits and lower-level motor systems may mean that GPi DBS has potential benefits besides its effects on low-level motor symptoms such as rigidity and bradykinesia.

\section{References}

Alexander GE, DeLong MR, Strick PL (1986) Parallel organization of functionally segregated circuits linking basal ganglia and cortex. Ann Rev Neurosci 9:357-381. CrossRef Medline

Amador SC, Hood AJ, Schiess MC, Izor R, Sereno AB (2006) Dissociating cognitive deficits involved in voluntary eye movement dysfunctions in 
Parkinson's disease patients. Neuropsychologia 44:1475-1482. CrossRef Medline

Antoniades C, Ettinger U, Gaymard B, Gilchrist I, Kristjánsson A, Kennard C, John Leigh R, Noorani I, Pouget P, Smyrnis N, Tarnowski A, Zee DS, Carpenter RH (2013a) An internationally standardised antisaccade protocol. Vision Res 84:1-5. CrossRef Medline

Antoniades CA, Buttery P, FitzGerald JJ, Barker RA, Carpenter RH, Watts C (2012) Deep brain stimulation: eye movements reveal anomalous effects of electrode placement and stimulation. PLoS One 7:e32830. CrossRef Medline

Antoniades CA, Xu Z, Carpenter RH, Barker RA (2013b) The relationship between abnormalities of saccadic and manual response times in Parkinson's disease. J Parkinsons Dis 3:557-563. CrossRef Medline

Antoniades CA, Demeyere N, Kennard C, Humphreys GW, Hu MT (2015) Antisaccades and executive dysfunction in early drug-naive Parkinson's disease: the discovery study. Mov Disord 30:843-847. CrossRef Medline

Aosaki T, Tsubokawa H, Ishida A, Watanabe K, Graybiel AM, Kimura M (1994) Responses of tonically active neurons in the primate's striatum undergo systematic changes during behavioral sensorimotor conditioning. J Neurosci 14:3969-3984. Medline

Averbeck BB, Lehman J, Jacobson M, Haber SN (2014) Estimates of projection overlap and zones of convergence within frontal-striatal circuits. J Neurosci 34:9497-9505. CrossRef Medline

Blekher T, Siemers E, Abel LA, Yee RD (2000) Eye movements in Parkinson's disease: before and after pallidotomy. Invest Ophthalmol Vis Sci 41:2177-2183. Medline

Bolam JP, Somogyi P, Takagi H, Fodor I, Smith AD (1983) Localization of substance P-like immunoreactivity in neurons and nerve terminals in the neostriatum of the rat: a correlated light and electron microscopic study. J Neurocytol 12:325-344. CrossRef Medline

Chan F, Armstrong IT, Pari G, Riopelle RJ, Munoz DP (2005) Deficits in saccadic eye-movement control in Parkinson's disease. Neuropsychologia 43:784-796. CrossRef Medline

DeSouza JF, Menon RS, Everling S (2003) Preparatory set associated with pro-saccades and anti-saccades in humans investigated with event-related FMRI. J Neurophysiol 89:1016-1023. CrossRef Medline

Draganski B, Kherif F, Klöppel S, Cook PA, Alexander DC, Parker GJ, Deichmann R, Ashburner J, Frackowiak RS (2008) Evidence for segregated and integrative connectivity patterns in the human basal ganglia. J Neurosci 28:7143-7152. CrossRef Medline

Fawcett AP, Moro E, Lang AE, Lozano AM, Hutchison WD (2005) Pallidal deep brain stimulation influences both reflexive and voluntary saccades in Huntington's disease. Mov Disord 20:371-377. CrossRef Medline

Fawcett AP, González EG, Moro E, Steinbach MJ, Lozano AM, Hutchison WD (2010) Subthalamic nucleus deep brain stimulation improves saccades in Parkinson's disease. Neuromodulation 13:17-25. CrossRef Medline

Guthrie M, Leblois A, Garenne A, Boraud T (2013) Interaction between cognitive and motor cortico-basal ganglia loops during decision making: a computational study. J Neurophysiol 109:3025-3040. CrossRef Medline

Guzman JN, Hernández A, Galarraga E, Tapia D, Laville A, Vergara R, Aceves J, Bargas J (2003) Dopaminergic modulation of axon collaterals interconnecting spiny neurons of the rat striatum. J Neurosci 23:8931-8940. Medline

Haber SN, Kim KS, Mailly P, Calzavara R (2006) Reward-related cortical inputs define a large striatal region in primates that interface with associative cortical connections, providing a substrate for incentive-based learning. J Neurosci 26:8368-8376. CrossRef Medline

Hallett PE (1978) Primary and secondary saccades to goals defined by instructions. Vision Res 18:1279-1296. CrossRef Medline

Hashimoto T, Elder CM, Okun MS, Patrick SK, Vitek JL (2003) Stimulation of the subthalamic nucleus changes the firing pattern of pallidal neurons. J Neurosci 23:1916-1923. Medline

Hood AJ, Amador SC, Cain AE, Briand KA, Al-Refai AH, Schiess MC, Sereno AB (2007) Levodopa slows prosaccades and improves antisaccades: an eye movement study in Parkinson's disease. J Neurol Neurosurg Psychiatry 78:565-570. CrossRef Medline

Kawaguchi Y, Wilson CJ, Emson PC (1990) Projection subtypes of rat neostriatal matrix cells revealed by intracellular injection of biocytin. J Neurosci 10:3421-3438. Medline

Kimura M (1986) The role of primate putamen neurons in the association of sensory stimuli with movement. Neurosci Res 3:436-443. CrossRef Medline

Kimura M (1992) Behavioral modulation of sensory responses of primate putamen neurons. Brain Res 578:204-214. CrossRef Medline

Kitagawa M, Fukushima J, Tashiro K (1994) Relationship between antisaccades and the clinical symptoms in Parkinson's disease. Neurology 44: 2285-2289. CrossRef Medline

Krack P, Batir A, Van Blercom N, Chabardes S, Fraix V, Ardouin C, Koudsie A, Limousin PD, Benazzouz A, LeBas JF, Benabid AL, Pollak P (2003) Five-year follow-up of bilateral stimulation of the subthalamic nucleus in advanced Parkinson's disease. N Engl J Med 349:1925-1934. CrossRef Medline

Liang L, DeLong MR, Papa SM (2008) Inversion of dopamine responses in striatal medium spiny neurons and involuntary movements. J Neurosci 28:7537-7547. CrossRef Medline

López-Huerta VG, Carrillo-Reid L, Galarraga E, Tapia D, Fiordelisio T, Drucker-Colin R, Bargas J (2013) The balance of striatal feedback transmission is disrupted in a model of parkinsonism. J Neurosci 33:49644975. CrossRef Medline

Meissner W, Leblois A, Hansel D, Bioulac B, Gross CE, Benazzouz A, Boraud $\mathrm{T}$ (2005) Subthalamic high frequency stimulation resets subthalamic firing and reduces abnormal oscillations. Brain 128:2372-2382. CrossRef Medline

Montgomery EB Jr, Gale JT (2008) Mechanisms of action of deep brain stimulation (DBS). Neurosci Biobehav Rev 32:388-407. CrossRef Medline

Munoz DP, Everling S (2004) Look away: the anti-saccade task and the voluntary control of eye movement. Nat Rev 5:218-228. CrossRef Medline

Pasquereau B, Nadjar A, Arkadir D, Bezard E, Goillandeau M, Bioulac B, Gross CE, Boraud T (2007) Shaping of motor responses by incentive values through the basal ganglia. J Neurosci 27:1176-1183. CrossRef Medline

Pierrot-Deseilligny C, Milea D, Müri RM (2004) Eye movement control by the cerebral cortex. Curr Opin Neurol 17:17-25. CrossRef Medline

Pinnock RA, McGivern RC, Forbes R, Gibson JM (2010) An exploration of ocular fixation in Parkinson's disease, multiple system atrophy and progressive supranuclear palsy. J Neurol 257:533-539. CrossRef Medline

Rivaud-Péchoux S, Vermersch AI, Gaymard B, Ploner CJ, Bejjani BP, Damier P, Demeret S, Agid Y, Pierrot-Deseilligny C (2000) Improvement of memory guided saccades in parkinsonian patients by high frequency subthalamic nucleus stimulation. J Neurol Neurosurg Psychiatry 68:381384. CrossRef Medline

Rivaud-Péchoux S, Vidailhet M, Brandel JP, Gaymard B (2007) Mixing proand antisaccades in patients with parkinsonian syndromes. Brain 130: 256-264. CrossRef Medline

Rodriguez-Oroz MC, Obeso JA, Lang AE, Houeto JL, Pollak P, Rehncrona S, Kulisevsky J, Albanese A, Volkmann J, Hariz MI, Quinn NP, Speelman JD, Guridi J, Zamarbide I, Gironell A, Molet J, Pascual-Sedano B, Pidoux B, Bonnet AM, Agid Y, et al. (2005) Bilateral deep brain stimulation in Parkinson's disease: a multicentre study with 4 years follow-up. Brain 128:2240-2249. CrossRef Medline

Singh A, Liang L, Kaneoke Y, Cao X, Papa SM (2015) Dopamine regulates distinctively the activity patterns of striatal output neurons in advanced parkinsonian primates. J Neurophysiol 113:1533-1544. CrossRef Medline

Staines WA, Atmadja S, Fibiger HC (1981) Demonstration of a pallidostriatal pathway by retrograde transport of HRP-labeled lectin. Brain Res 206: 446-450. CrossRef Medline

Straube A, Ditterich J, Oertel W, Kupsch A (1998) Electrical stimulation of the posteroventral pallidum influences internally guided saccades in Parkinson's disease. J Neurol 245:101-105. CrossRef Medline

Taverna S, Ilijic E, Surmeier DJ (2008) Recurrent collateral connections of striatal medium spiny neurons are disrupted in models of Parkinson's disease. J Neurosci 28:5504-5512. CrossRef Medline

Temel Y, Visser-Vandewalle V, Carpenter RH (2008) Saccadic latency during electrical stimulation of the human subthalamic nucleus. Curr Biol 18:R412-R414. CrossRef Medline

Temel Y, Visser-Vandewalle V, Carpenter RH (2009) Saccadometry: a novel clinical tool for quantification of the motor effects of subthalamic nucleus stimulation in Parkinson's disease. Exp Neurol 216:481-489. CrossRef Medline

Terao Y, Fukuda H, Ugawa Y, Hikosaka O (2013) New perspectives on the 
pathophysiology of Parkinson's disease as assessed by saccade performance: a clinical review. Clin Neurophysiol 124:1491-1506. CrossRef Medline

Vermersch AI, Rivaud S, Vidailhet M, Bonnet AM, Gaymard B, Agid Y, Pierrot-Deseilligny C (1994) Sequences of memory-guided saccades in Parkinson's disease. Ann Neurol 35:487-490. CrossRef Medline

Wark HA, Garell PC, Walker AL, Basso MA (2008) A case report on fixation instability in Parkinson's disease with bilateral deep brain stimulation implants. J Neurol Neurosurg Psychiatry 79:443-447. CrossRef Medline

Wilson CJ, Groves PM (1980) Fine structure and synaptic connections of the common spiny neuron of the rat neostriatum: a study employing intracellular inject of horseradish peroxidase. J Comp Neurol 194:599_ 615. CrossRef Medline

Yoshida A, Tanaka M (2009) Enhanced modulation of neuronal activity during antisaccades in the primate globus pallidus. Cereb Cortex 19:206217. CrossRef Medline

Yoshida A, Tanaka M (2015) Two types of neurons in the primate globus pallidus external segment play distinct roles in antisaccade generation. Cereb Cortex pii:bhu308. CrossRef Medline

Yugeta A, Terao Y, Fukuda H, Hikosaka O, Yokochi F, Okiyama R, Taniguchi M, Takahashi H, Hamada I, Hanajima R, Ugawa Y (2010) Effects of STN stimulation on the initiation and inhibition of saccade in Parkinson disease. Neurology 74:743-748. CrossRef Medline 